\title{
CRÓNICA DE JURISPRUDENCIA DEL TRIBUNAL EUROPEO DE DERECHOS HUMANOS, ENERO-ABRIL 2018
}

\author{
MARTA CABRERA MARTÍN' \\ Tribunal Europeo de Derechos Humanos \\ Marta.Cabrera.Martin@echr.coe.int
}

Cómo citar/Citation

Cabrera Martín, M. (2018).

Crónica de jurisprudencia del Tribunal Europeo de Derechos Humanos,

enero-abril 2018.

Revista de Derecho Comunitario Europeo, 60, 761-789.

doi: https://doi.org/10.18042/cepc/rdce.60.08

\section{SUMARIO}

I. INTRODUCCIÓN. II. PRINCIPALES SENTENCIAS Y DECISIONES DEL TEDH: 1. Derecho al respeto a la vida privada y familiar (artículo 8 del CEDH). 2. Libertad de expresión (artículo 10 del CEDH). 3. Solicitud de revisión (artículo 80 del Reglamento del TEDH). III. REFERENCIAS AL DERECHO DE LA UE EN LA JURISPRUDENCIA DEL TEDH. IV. ESPAÑA Y EL TRIBUNAL EUROPEO DE DERECHOS HUMANOS.

\footnotetext{
1 Letrada de apoyo del Tribunal Europeo de Derechos Humanos.
} 


\section{INTRODUCCIÓN}

La presente crónica tiene por objeto servir de referencia sobre la prolífica actividad jurisprudencial del Tribunal Europeo de Derechos Humanos (en adelante, TEDH o el Tribunal) durante el período comprendido entre los meses de enero y abril de 2018 .

Debido a la relativamente alta producción de sentencias por parte del Tribunal con respecto a España en este cuatrimestre, se ha optado por centrar la presente crónica, en mayor proporción, en dicha jurisprudencia.

En primer lugar se realizará un somero análisis de las sentencias más relevantes por su impacto en el desarrollo del contenido, naturaleza y ámbito de aplicación de los derechos contenidos en el Convenio Europeo de Derechos Humanos (en adelante, CEDH o el Convenio). Para ello, nos centraremos en aquellas sentencias relativas a los arts. 8 (derecho al respeto a la vida privada y familiar) y 10 (libertad de expresión) del Convenio, para finalizar analizando una importante sentencia que versa sobre el mecanismo de «revisión» previsto en el art. 80 del Reglamento.

El siguiente apartado está destinado a comentar aquellos pronunciamientos en los que el Tribunal ha analizado instrumentos legales y jurisprudencia de la Unión Europea (en adelante, UE) como etapa previa para fundamentar algunos de sus fallos.

Finalmente, se abordarán las sentencias más relevantes del Tribunal dictadas contra España a lo largo del señalado cuatrimestre.

\section{PRINCIPALES SENTENCIAS Y DECISIONES DEL TEDH}

\section{DERECHO AL RESPETO A LA VIDA PRIVADA Y FAMILIAR (ARTÍCULO 8 DEL CEDH)}

En primer lugar, analizaremos la interesante sentencia recaída en el caso Fédération nationale des associations et des syndicats sportifs (FNASS) y otros $c$. Francia $^{2}$, en el cual el Tribunal analizó la compatibilidad del art. 8 del Convenio con el impacto de ciertas medidas contra el dopaje de las personas deportistas profesionales.

Las demandas fueron presentadas por demandantes individuales, así como por varias asociaciones y sindicatos deportivos. Las mismas tenían como

2 Fédération nationale des associationdes syndicats sportifs (FNASS) and others $v$. France, nos. 48151/11 and 77769/13. 
objeto cuestionar el impacto y compatibilidad de las «medidas de localización» o «sistema de rastreo» de los deportistas con su derecho a la vida privada y familiar (así como el derecho a la libertad de circulación). Este tipo de medidas suponían la obligación del deportista de informar detalladamente sobre su ubicación diaria durante un período de tres meses, incluido el tiempo en el que no se estaba realizando una actividad relacionada con actividades deportivas. También se puso el foco en la obligación de estar disponible durante una hora al día (en un espacio de tiempo entre las seis de la mañana y nueve de la noche) para ser sometidos a un test sin previo aviso. Según los demandantes, este tipo de medidas tenía una repercusión negativa en la planificación de su vida diaria y familiar, así como en el disfrute de su tiempo en su casa (right to home), toda vez que los test sin previo aviso podían tener lugar en la propia casa del deportista. Con todo, los demandantes consideraban que este tipo de medidas tenían una naturaleza intrusiva y contraria al art. 8 del CEDH.

En primer lugar, el Tribunal analizó quién estaba legitimado para interponer la demanda. Así, el TEDH concluyó que las asociaciones y sindicatos no podían considerarse víctimas en el sentido del art. 34 del Convenio, así como tampoco podían considerarse víctimas algunos de los demandantes individuales que no se habían visto afectados por las medidas ${ }^{3}$. En cuanto a las demandas presentadas por los deportistas individuales restantes que sí acreditaron ser objetivo de las medidas señaladas, estas fueron declaradas admisibles ratione persona $e^{4}$.

El interés del presente caso radica en el hecho de que es la primera vez que el Tribunal ha podido examinar de manera detallada la aplicación del Convenio en el ámbito deportivo. Para ello, el Tribunal tuvo como referencia numerosos instrumentos europeos e internacionales encargados de establecer estándares deportivos, tales como la Convención Internacional contra el Dopaje en el Deporte de la UNESCO, el Código Mundial Antidopaje (no vinculante) y el Convenio contra el Dopaje del Consejo de Europa. También cabe destacar que la Agencia Mundial Antidopaje, la cual fue la encargada de elaborar el mencionado Código Mundial Antidopaje, intervino en el presente procedimiento como «tercero interviniente».

En cuanto al fondo del asunto, el TEDH señaló en primer lugar que, efectivamente, el requerimiento de localización permanente suponía una injerencia en la vida privada, familiar y el hogar amparadas por el art. 8 del Convenio $^{5}$. En particular, la obligación de estar presente en un lugar determinado

\footnotetext{
Ibid., párrs. 91 a 103.

Ibid., párr. 103.

Ibid., párrs. 155 a 159.
} 
cada día de la semana por un espacio de una hora tenía un impacto sobre la vida privada de los demandantes y afectaba al derecho al disfrute de la vida familiar, toda vez que en una mayoría de ocasiones este tipo de obligación implicaba que el demandante tuviera que estar en el domicilio designado a los efectos de poder eventualmente ser sometido a un control antidoping sin previo aviso.

Al ser una injerencia del Estado, el TEDH pasó a analizar si la misma estaba, en primer lugar, prevista en la ley, lo cual tuvo respuesta afirmativa ${ }^{6}$. A continuación, el TEDH tuvo que determinar si dicho tipo de medidas perseguía un fin legítimo. El Tribunal concluyó que, efectivamente, el fin era legítimo, toda vez que existía una necesidad de combatir el dopaje, impedir que el uso de este tipo de sustancias hiciera que los deportistas no estuvieran en las mismas condiciones para competir, así como también impedir que se incitara a los deportistas amateurs a utilizar este tipo de productos, inter alia ${ }^{7}$.

A continuación, el Tribunal centró su análisis en si la medida era «necesaria en una sociedad democrática». A este respecto el Tribunal subrayó dos puntos a tener en cuenta a la hora de determinar si existe una «necesidad social imperiosa» (pressing social need) para imponer tales medidas. En primer lugar, el Tribunal observó que numerosos estudios científicos acreditaban los efectos nocivos del dopaje en la salud de los profesionales del deporte, así como del peligro de utilizar este tipo de sustancias no solo por parte de dichos profesionales, sino también por gente joven, lo cual convertía el asunto en una cuestión de salud pública ${ }^{8}$. En segundo lugar, el TEDH destacó que existía un consenso europeo e internacional sobre la necesidad por parte de los Estados de adoptar medidas en contra del dopaje en el deporte. A la vista de las difíciles cuestiones científicas, legales y éticas que rodean este asunto, los Estados debían gozar de un «amplio margen de apreciación»". El Tribunal observó además que Francia, al igual que otros Estados miembros del Consejo de Europa, había ratificado la Convención Internacional contra el Dopaje en el Deporte de la UNESCO y había implementado las medidas de localización previstas en el Código Mundial Antidopaje. En vista de lo anterior, las acciones adoptadas por el Estado francés estaban en consonancia con el consenso internacional sobre la necesidad de combatir el dopaje mediante medidas de localización ${ }^{10}$.

$6 \quad$ Ibid., párrs. 160 a 163.

7 Ibid., párrs. 164 a 166.

$8 \quad$ Ibid., párrs. 171 a 177.

9 Ibid., párr. 182.

10 Ibid., párr. 183. 
Finalmente, el Tribunal debía determinar si se había logrado un «equilibrio justo» entre las obligaciones del Estado francés y los derechos de los demandantes amparados por el art. 8 del CEDH. Para determinar lo anterior, el Tribunal tuvo en consideración lo siguiente: 1) el hecho de que la lista de personas sometidas a estas medidas tenía una duración de un año; 2) la posibilidad de los deportistas de indicar dónde y cuándo podían ser localizados, permitiéndose la posibilidad de que fuera incluso en su propia casa: 3 ) el hecho de que la implementación de este tipo de medidas disponía de una serie de garantías que permitía a los deportistas impugnar ante los tribunales nacionales su inclusión en la lista anual de «investigados», así como las sanciones que se derivaran del resultado de dichos controles ${ }^{11}$. Todo lo anterior llevó al TEDH a concluir que, en el presente caso, no se produjo una violación del art. 8 del Convenio ${ }^{12}$.

Por otro lado, en el caso Lozovyye c. Rusia ${ }^{13}$, el Tribunal tuvo oportunidad de analizar las obligaciones positivas de un Estado a la hora de informar a unos padres sobre la muerte de su hijo.

En 1 de diciembre de 2005 el hijo de los demandantes fue asesinado en San Petersburgo. Las autoridades iniciaron un procedimiento penal contra el presunto asesino e intentaron identificar a los familiares de la víctima para otorgarles el estatus de víctima en el procedimiento penal. Una semana más tarde el hijo de los demandantes fue enterrado en San Petersburgo. En el registro del cementerio constaba el nombre del hijo de los demandantes, así como el hecho de que el cuerpo no había sido reclamado. Si bien se adoptaron por parte de la Fiscalía algunas medidas para poder identificar a los familiares, esta no consiguió encontrarles.

El 2 de febrero de 2006, los demandantes, al descubrir el trágico suceso, contactaron con las autoridades y les informaron de su intención de formar parte del procedimiento penal, lo cual fue concedido. Los demandantes también solicitaron poder exhumar los restos de su hijo. Dos días después lo pudieron enterrar en su ciudad de origen, Belomorsk. Los demandantes acudieron ante los tribunales nacionales y ejercitaron una acción contra la Fiscalía y el Ministerio de Finanzas reclamando una indemnización por daños morales y materiales, toda vez que habían tenido que sufragar los gastos de exhumación y transporte de su hijo, así como iniciar un procedimiento buro-

11 Ibid., párr. 187.

12 Ibid., párr. 191.

13 Lozovyye v. Russia, no. 4587/09. Cabe señalar que dicha sentencia no ha alcanzado, al momento de redacción de la presente crónica, firmeza, de conformidad con lo estipulado en el art. 44.2 del Convenio. 
crático de dos semanas para obtener el permiso correspondiente. Asimismo, los demandantes habían sufrido un daño moral en tanto que no supieron nada del paradero de su hijo por un amplio período de tiempo. La solicitud de indemnización fue denegada.

Los demandantes acudieron ante el TEDH y alegaron que se había producido una violación del art. 8 del Convenio en tanto que su derecho a la vida privada y familiar había sido conculcado. El Tribunal dio la razón a los demandantes y consideró que, efectivamente, las autoridades nacionales no actuaron con una diligencia razonable y, por tanto, no dieron cumplimiento a sus obligaciones positivas ${ }^{14}$.

El interés del presente caso radica en el hecho de que es la primera vez que el Tribunal aplica el art. 8 a una situación en la que el Estado no cumple con su obligación de informar a los familiares de la muerte de un allegado. Esta obligación supone una obligación positiva orientada a la protección de los valores garantizados por el art. 8. En concreto, el TEDH señaló lo siguiente:

El Tribunal [...] considera que en una situación como la presente, en donde sólo el Estado [...] tenía constancia de la muerte [de la víctima], existe una obligación por parte de dichas autoridades que adoptar como mínimo medidas razonables para asegurar que los familiares supervivientes sean informados ${ }^{15}$.

Asimismo, cabe destacar que el TEDH también observó que la legislación nacional aplicable a este tipo de situaciones no era clara al respecto, si bien esto no era suficiente como para declarar una violación independiente del art. $8^{16}$. La cuestión relevante era determinar si la respuesta de las autoridades había sido adecuada o no. Al analizar las circunstancias concretas del presente caso, el Tribunal observó que el Estado disponía de diversos medios para determinar la filiación de la víctima. El Tribunal de Distrito había elaborado una listado con todos los documentos y pruebas obtenidas que podían haber servido como información necesaria para poder encontrar a los demandantes (por ejemplo: llamadas de teléfono, amigos del hijo, documentos oficiales, etc.). El Gobierno no dio ninguna explicación de por qué no se utilizó ninguno de estos medios ${ }^{17}$. Asimismo, el Tribunal observó que la decisión de enterrar al hijo de los demandantes se adoptó incluso antes de que terminara el

\footnotetext{
14 Ibid., párr. 46.

15 Ibid., párr. 38.

16 Ibid., párr. 42

17 Ibid., párr. 44.
} 
procedimiento de búsqueda de los familiares. Por todo lo anterior, el Tribunal consideró que se había producido una violación del art. 8 del $\mathrm{CEDH}$.

\section{LIBERTAD DE EXPRESIÓN (ARTÍCULO 10 DEL CEDH)}

Una sentencia que merece especial atención, y que a fecha de elaboración de la presente crónica ya ha alcanzado su firmeza, es la recaída en el caso Sekmadienis LTD. v. Lituania $^{18}$.

En el presente caso el demandante era una firma de ropa que había realizado una campaña publicitaria en la que dos modelos representaban a Jesús y María y tenían una aureola sobre sus cabezas. Las imágenes iban acompañadas de las frases «iJesús, qué pantalones!», «QQuerida María, qué vestido!», «iJesús, María, lo que lleváis puesto!». La representación religiosa tenía, por tanto, un efecto cómico, lo cual llevó a cientos de personas a presentar una denuncia contra la compañía, lo que derivó en un procedimiento sancionador contra la demandante. Los tribunales nacionales consideraron que los anuncios en cuestión eran contrarios a la moral pública y violaban la Ley sobre Publicidad vigente en el momento de los hechos. También se consideró que el uso de símbolos religiosos había sido realizado por motivos superfluos y que la campaña promovía un «estilo de vida incompatible con los principios de una persona religiosa». La demandante fue multada.

La demandante acudió ante el TEDH arguyendo que se había producido una violación de su derecho a la libertad de expresión amparado por el art. 10 del Convenio. El Tribunal falló a favor de la demandante. En concreto, el Tribunal consideró que el Estado lituano se había excedido en el margen de apreciación en el ámbito del lenguaje comercial, tal y como así lo recogía la asentada jurisprudencia del Tribunal ${ }^{19}$.

Una vez determinado que la injerencia realizada por el Estado estaba amparada en la ley y perseguía un fin legítimo, el Tribunal se centró, entre otras cosas, en establecer si los tribunales nacionales habían brindado razones suficientes para justificar la existencia de una «necesidad social imperiosa» que amparara la restricción realizada.

En primer lugar, el TEDH observó que los anuncios objeto de sanción no parecían contener un carácter gratuitamente ofensivo o profano, y que tampoco incitaban al ataque a algún tipo de religión en una manera abusiva ${ }^{20}$.

18 Sermadienis LTD. v. Lithuania, no. 69317/14.

19 Ver Markt intern Verlag GmbH and Klaus Beermann v. Germany, no. 10572/83, párr. 33; Mouvement raëlien suisse v. Switzerland [GC], no. 16354/06, párr. 61.

20 Sermadienis LTD. v. Lithuania, cit. supra, párr. 77. 
En segundo lugar, el TEDH consideró que los tribunales nacionales no habían esgrimido razones suficientes para considerar que los anuncios eran contrarios a la moral pública. Para el tribunal, las explicaciones dadas eran meramente «declarativas e imprecisas» ${ }^{21}$. Además, el TEDH hizo una observación interesante al analizar que las decisiones nacionales, al hacer referencia a las «personas religiosas», habían solo consultado a la Iglesia católica, lo cual equiparaba la moral únicamente con la moral de una única tradición religiosa ${ }^{22}$. En tercer lugar, el TEDH señaló que, incluso en el caso en el que una mayoría de la población lituana considerara que la publicidad en cuestión era ofensiva, el hecho de que los derechos de una minoría existieran con el condicionante de que fueran aceptados por la mayoría sería incompatible con el Convenio, ya que en tal caso el derecho a la libertad de expresión se convertiría en algo meramente teórico y no práctico ${ }^{23}$.

El TEDH concluyó por tanto que las autoridades nacionales habían otorgado absoluta primacía a la protección de los sentimientos religiosos sin tener en cuenta de manera adecuada el derecho a la libertad de expresión de la demandante, con lo cual se produjo una violación del art. 10 del $\mathrm{CEDH}^{24}$.

\section{SOLICITUD DE REVISIÓN (ARTÍCULO 80 DEL REGLAMENTO DEL TEDH)}

El 20 de marzo de 2018 la Gran Sala emitió una importante sentencia que viene a interpretar la aplicación del art. 80.1 del Reglamento, relativo al recurso de revisión. Dicho artículo señala lo siguiente: «En el caso de que se descubra un hecho el cual, por su naturaleza, podría haber ejercido una influencia decisiva en un asunto sobre un caso ya tratado y que, a la época de la sentencia, era desconocido por el Tribunal y no podría ser razonablemente conocido por una de las partes, ésta puede, en el plazo de seis meses a partir del conocimiento del hecho descubierto, acudir ante el Tribunal e interponer una demanda de revisión de la sentencia en cuestión».

La sentencia en cuestión fue la recaída en el caso Irlanda c. Reino Unido ${ }^{25}$. Cabe recordar primeramente que el Tribunal había emitido una sentencia en el presente asunto el 18 de enero de 1978, en virtud de la cual el TEDH había declarado que el Estado demandando había hecho uso de una serie de métodos interrogatorios contra catorce detenidos en violación del art. 3 del

\footnotetext{
Ibid., párr. 79.

Ibid., párrs. 79 y 80.

Ibid., párr. 82.

Ibid., párrs. 83 y 84 .

Ireland v. the United Kingdom [GC, Revision], no. 5310/71.
} 
Convenio y que dichas técnicas habían constituido un trato inhumano y degradante. El matiz de dicha sentencia radicó en que, de manera contraria a lo que había propuesto la antigua Comisión Europea de Derechos Humanos, no se consideró que se había producido tortura.

El 4 de junio de 2014 el Estado irlandés interpuso un recurso de revisión, todo ello de conformidad con lo estipulado en el ya mencionado art. 80 del Reglamento. El Estado irlandés solicitó una revisión únicamente en cuanto a la calificación de los hechos enjuiciados con respecto a cinco específicas técnicas de interrogatorio. Para fundamentar dicho recurso se basaron en un documental de televisión de fecha 4 de junio de 2014 que puso su foco sobre una serie de documentos que, en caso de haber sido conocidos por el Tribunal en el momento de juzgar los hechos, podrían haber tenido una influencia decisiva en el fallo y en la calificación de tortura en vez de tratos inhumanos y degradantes.

$\mathrm{Al}$ contrario que en otros recursos de revisión presentados ante el Tribunal, el presente recurso no tenía como objetivo modificar el fallo del Tribunal, sino que lo que se pretendía es que se reconociera que, además de producirse tratos inhumanos y degradantes, se habían producido actos de tortura, todo ello en violación del art. 3 del Convenio.

Esta es la primera vez que el Tribunal ha tenido que considerar aplicar su propia jurisprudencia sobre el art. 80 del Reglamento en un caso interestatal, surgido además tras el paso de un largo lapso de tiempo desde la emisión de la sentencia. El TEDH volvió a destacar que el recurso de revisión es un mecanismo excepcional, y ello a la vista del carácter definitivo de las sentencias del Tribunal ${ }^{26}$. Es por ello que una solicitud de revisión estaba siempre sujeta a un «estricto escrutinio»"

Por un lado, el Tribunal consideró que el recurso de revisión había sido interpuesto dentro del plazo establecido para ello $^{28}$. El Tribunal, además, observó que el Gobierno irlandés había recibido en fecha anterior al documental señalado numerosos documentos relevantes que informaban de nuevos hechos. El Gobierno irlandés no había mostrado una actitud pasiva tras recibir dichos documentos y, por tanto, no podría ser criticado por ello ${ }^{29}$.

La cuestión central radicó en el hecho de que los documentos remitidos por el Estado demandante demostraban la existencia de «nuevos hechos» y si

\footnotetext{
26 Ibid., párr. 32.

27 Ver, por ejemplo, párrs. 93 y 122

28 Ibid., párr. 80.

29 Ibid., párr. 94.
} 
los mismos podrían haber tenido una influencia decisiva en las conclusiones de la sentencia originaria ${ }^{30}$.

Finalmente, el TEDH consideró que las pruebas y documentos aportados no demostraban la existencia de nuevos hechos y, sobre todo, que se hubiera engañado a la Comisión Europea de Derechos Humanos en su momento ${ }^{31}$, por lo que la solicitud de revisión fue finalmente rechazada.

\section{REFERENCIAS AL DERECHO DE LA UE EN LA JURISPRUDENCIA DEL TEDH}

Tal y como veremos a continuación, el TEDH ha acudido en numerosas ocasiones a textos de la UE (derecho derivado, jurisprudencia, opiniones de grupos especializados, etc.) para analizar cuestiones de gran relevancia dentro del escenario europeo, tan variante. Lo anterior sirve para ilustrar los innegables paralelismos existentes en la manera de interpretar los tratados de derechos humanos y observar cómo ambas jurisdicciones toman en consideración de manera creciente el enfoque de la otra en materia de protección de los derechos humanos.

Un primer ejemplo es la sentencia recaída en el caso Nä̈t-Liman c. Sui$z a^{32}$, en la que la Gran Sala analizó la ausencia de una jurisdicción universal en procedimientos civiles que versaban sobre casos de tortura.

En el año 2001 un antiguo ministro de interior de Túnez estuvo hospitalizado brevemente en Suiza. El demandante era un refugiado político con residencia en Suiza que en aquella época había interpuesto una querella contra dicho ministro por actos de tortura sufridos en el año 1992. Dicho ministro se fue de Suiza y el procedimiento no pudo continuar, razón por la cual el demandante interpuso una demanda civil reclamando la correspondiente compensación. Los juzgados suizos adujeron que no tenían jurisdicción, toda vez que el denominado "foro de necesidad» (forum necessitatis) solo se aceptaba cuando el caso tenía una suficiente conexión con Suiza.

El TEDH analizó en primer lugar si se aplicaba el art. 6.1 al presente caso, en su vertiente civil, y terminó concluyendo que efectivamente sí era de aplicación $^{33}$. En lo que se refiere al fondo del asunto, el TEDH analizó si la

\footnotetext{
30 Ibid., párrs. 96 a 103.

31 Ibid., párrs. 108 a 113 y 114 a 118.

32 Naït-Liman v. Switzerland [GC], no. 51357/07.

33 Ibid., párrs. 103 a 111.
} 
restricción impuesta por el Estado suizo perseguía un fin legítimo y era proporcional al mismo, concluyendo de manera afirmativa ${ }^{34}$.

En cuanto a la proporcionalidad de la restricción, el TEDH observó que no existía ninguna norma de derecho internacional que obligara a Suiza a acceder a que el caso del demandante pudiera ser analizado por los tribunales internos ${ }^{35}$.

Asimismo, y con respecto a la existencia de un foro de necesidad, el Tribunal también hizo especial referencia al Reglamento n. ${ }^{\circ}$ 650/2012, relativo a la competencia, la ley aplicable, el reconocimiento y la ejecución de las resoluciones, a la aceptación y la ejecución de los documentos públicos en materia de sucesiones mortis causa y a la creación de un certificado sucesorio europeo $^{36}$.

Por otro lado, el TEDH también hizo referencia al Reglamento n. ${ }^{\circ}$ $1215 / 2012$, relativo a la competencia judicial, el reconocimiento y la ejecución de resoluciones judiciales en materia civil y mercantil ${ }^{37}$, destacando su art. 11, relativo al forum necessitatis, cuyo contenido es el siguiente:

Cuando ningún tribunal de un Estado miembro sea competente con arreglo a otras disposiciones del presente Reglamento, los tribunales de un Estado miembro podrán resolver, en casos excepcionales, sobre la sucesión si resultase imposible o no pudiese razonablemente iniciarse o desarrollarse el proceso en un tercer Estado con el cual el asunto tuviese una vinculación estrecha.

El asunto deberá tener una vinculación suficiente con el Estado miembro del tribunal que vaya a conocer de él".

En el presente caso, por tanto, el margen de apreciación otorgado al Estado suizo fue amplio y se consideró que no existieron elementos arbitrarios

34 Ibid., párrs. 128 y 216.

35 Ibid., párr. 202.

36 Reglamento (UE) n. ${ }^{\circ}$ 650/2012 del Parlamento Europeo y del Consejo, de 4 de julio de 2012, relativo a la competencia, la ley aplicable, el reconocimiento y la ejecución de las resoluciones, a la aceptación y la ejecución de los documentos públicos en materia de sucesiones mortis causa y a la creación de un certificado sucesorio europeo (DO L 201 de 27.7.2012, p. 107).

37 Reglamento (UE) n. ${ }^{\circ}$ 1215/2012 del Parlamento Europeo y del Consejo de 12 de diciembre de 2012 relativo a la competencia judicial, el reconocimiento y la ejecución de resoluciones judiciales en materia civil y mercantil (DO L 351 de 20.12.2012, p. $1)$. 
o manifiestamente irracionales en la interpretación realizada por el Tribunal Supremo Federal suizo ${ }^{38}$.

Por otro lado, en el caso Correia Matos c. Portuga ${ }^{39}$, también analizado por la Gran Sala del TEDH, el Tribunal acudió a diversos instrumentos dimanantes de la UE para poder analizar el caso. A modo de síntesis, destacaremos que el presente caso versaba primordialmente sobre la imposibilidad del demandante para asumir su propia defensa en un procedimiento penal y la posible conculcación de los apdos. 1 y 3c) del art. 6 del Convenio. Cabe señalar que en el presente caso la licencia del demandante para ejercer había sido suspendida por el Colegio de Abogados en el momento de los procedimientos seguidos contra él por haber insultado a un juez.

En el presente caso, el TEDH observó que los tribunales internos habían basado su decisión en una jurisprudencia constante del Tribunal Constitucional, el Tribunal Supremo y los tribunales de apelaciones. Asimismo, a la vista de la libertad que tienen los Estados a la hora de elegir los medios para cumplir con las exigencias del apdo. 3c) del art. 6 del Convenio, y a la vista del objetivo intrínseco de dicho precepto para contribuir en la aseguración de la equidad en un procedimiento penal, los estándares adoptados por dichos Estados así como los desarrollos internacionales no eran determinantes ${ }^{40}$. El TEDH, además, tuvo en cuenta lo argüido por el Estado portugués en cuanto a que esta limitación estaba diseñada no para limitar la defensa del demandante, sino para asegurar una defensa efectiva.

Lo anterior se justificaba aún más en el presente caso, en el cual el demandante tenía suspendida temporalmente su licencia y por tanto ni siquiera podía prestar asistencia letrada a terceros. Asimismo, el demandante ya había sido imputado por haber insultado a un juez. Todo lo anterior hacía razonable pensar que el demandante, de actuar representándose a sí mismo, podría haber carecido de la actitud objetiva y "desapasionada» que se necesita para ejercer una defensa efectiva ${ }^{41}$.

Asimismo, el TEDH acudió a la Carta de los Derechos Fundamentales de la Unión Europea e hizo referencia al art. 47.2, el cual dispone que «toda persona tiene derecho a que su causa sea oída equitativa y públicamente y dentro de un plazo razonable por un juez independiente e imparcial, establecido previamente por la ley. Toda persona podrá hacerse aconsejar, defender y representar».

\footnotetext{
38 Ibid., párrs. 205 a 216.

39 Correia de Matos v. Portugal [GC], no. 56402/12.

40 Ibid., párr. 137.

41 Ibid., párr. 147.
} 
El Tribunal también hizo referencia a los arts. 48, relativo a la presunción de inocencia, y 52, relativo al alcance y limitaciones de los derechos reconocidos en la Carta. Por otro lado, el TEDH también acudió a la Directiva 2014/48/UE, la cual regula, entre otros, la asistencia del letrado en los procesos penales, y, en particular, a los arts. 3 (derecho a la asistencia de letrado en los procesos penales), 9 (renuncia) y 14 (cláusula de no regresión) ${ }^{42}$.

El Tribunal a continuación observó que la legislación portuguesa otorgaba al acusado numerosos mecanismos para participar en persona a lo largo del procedimiento, tales como, estar presente en todas las fases del mismo, realizar comentarios o permanecer en silencio, y remitir observaciones y peticiones las cuales además no necesitaban ser firmadas por un letrado o letrada. Asimismo, la legislación portuguesa otorgaba al acusado el derecho a la última palabra, en virtud del cual este podía ser oído antes de que se dictara la oportuna senten-

42 Directiva 2013/48/UE del Parlamento Europeo y del Consejo, de 22 de octubre de 2013, sobre el derecho a la asistencia de letrado en los procesos penales y en los procedimientos relativos a la orden de detención europea, y sobre el derecho a que se informe a un tercero en el momento de la privación de libertad y a comunicarse con terceros y con autoridades consulares durante la privación de libertad (DO L 294 de 6.11.2013, p. 1). Los pasajes más relevantes eran:

«Artículo 3 - Derecho a la asistencia de letrado en los procesos penales

1. Los Estados miembros velarán por que los sospechosos y acusados tengan derecho a ser asistidos por un letrado en el momento y del modo que les permita ejercer sus derechos de defensa en la práctica y de manera efectiva.

[...]

4. Los Estados miembros se esforzarán por difundir información general con el fin de facilitar a los sospechosos o acusados la designación de un letrado [...].

Artículo 9 - Renuncia

1. Sin perjuicio de si la normativa nacional exige la presencia o la asistencia obligatoria de un letrado, los Estados miembros garantizarán que, en lo que se refiere a toda renuncia a un derecho contemplado en los artículos 3 y 10:

a) se haya facilitado al sospechoso o acusado, verbalmente o por escrito, información clara y suficiente en un lenguaje sencillo y comprensible sobre el contenido de dicho derecho y las posibles consecuencias de renunciar a él, y

b) la renuncia sea voluntaria e inequívoca.

[...]

Artículo 14 - Cláusula de no regresión

Ninguna disposición de la presente Directiva se interpretará en el sentido de limitar o derogar los derechos o las garantías procesales que estén reconocidos al amparo de la Carta, del CEDH, del Pacto o de, otras disposiciones pertinentes de Derecho internacional o de la normativa de los Estados miembros que garantice un nivel de protección más elevado». 
cia ${ }^{43}$. Tras analizar la situación específica del demandante y cómo transcurrió el procedimiento, así como a la vista del marco legal existente, el Tribunal consi deró, en una decisión de nueve votos contra ocho, que no se había producido una violación de los apdos. 1 y 3c) del art. 6 del Convenio ${ }^{44}$.

Por último, también citaremos la sentencia Baydar c. Países Bajos ${ }^{45}$, la cual versa sobre la compatibilidad del art. 6.1 del Convenio con el rechazo a formular una cuestión prejudicial ante el Tribunal de Justicia de la Unión Europea (en adelante, TJUE).

En este caso en particular, el demandante había solicitado en el recurso de casación ante el Tribunal Supremo la formulación de una cuestión prejudicial. Dicho recurso fue rechazado por el Alto Tribunal haciendo referencia al art. 81.1 de la Ley de Organización Judicial y al señalar que «las quejas presentada no hacían necesario determinar cuestiones legales en el interés de una uniformidad legal o un desarrollo legal».

El demandante acudió ante el TEDH arguyendo que se había producido una violación del art. 6.1 por cuanto la decisión de rechazo no estaba suficientemente motivada. Así, mientras el TEDH tiene declarado que los tribunales nacionales, cuando actúan como últimas instancias, están obligados a motivar debidamente los rechazos a las solicitudes de cuestiones prejudiciales ante el $\mathrm{TEDH}^{46}$, también es cierto que al amparo del referido art. 6.1 los altos tribunales podían desestimar un recurso realizando una mera referencia al precepto legal en virtud del cual dicho recurso se desestimaba.

El TEDH observó que el citado art. 81 de la Ley de Organización Judicial permitía al Tribunal Supremo desestimar un recurso de casación por carecer de razones que justificaran la revocación de la sentencia y por no dar razones que sustentaran la «necesidad de determinar una cuestión legal». Asimismo, el art. 80 del citado cuerpo legal también permitía la desestimación de un recurso por "carecer de posibilidades de éxito»" ${ }^{47}$. El objetivo de estos preceptos era intentar mantener un plazo razonable de duración de los procedimientos y permitir a este tipo de órganos concentrar su función principal en asegurar la aplicación uniforme de la ley, así como su correcta interpretación ${ }^{48}$.

3 Ibid., párrs. 152 a 159.

44 Ibid., párrs. 160 a 169.

45 Baydar v. the Netherlands, no. 55385/14. Cabe señalar que dicha sentencia no ha alcanzado, al momento de redacción de la presente crónica, firmeza, de conformidad con lo estipulado en el art. 44.2 del Convenio.

46 Véase, entre otros, Dhahbi v. Italy, no. 12120/09.

47 Ibid., párr. 47.

48 Ibid., párr. 47. 
Por otro lado, el Tribunal hizo referencia a varios instrumentos de la UE, así como a la jurisprudencia que emana del TJUE. En primer lugar, procedió a citar el art. 267 TFUE, el cual regula la jurisdicción del TJUE sobre las cuestiones prejudiciales. Adicionalmente, el Tribunal destacó la Recomendación realizada por el TJUE n. ${ }^{\circ}$ 2016/C 439/01, a los órganos jurisdiccionales nacionales, relativas al planteamiento de cuestiones prejudiciales ${ }^{49}$, y, en particular, al art. 3, el cual señala que:

El Tribunal de Justicia ejerce su competencia para pronunciarse con carácter prejudicial sobre la interpretación o la validez del Derecho de la Unión exclusivamente a iniciativa de los órganos jurisdiccionales nacionales, con independencia de que las partes del litigio principal hayan solicitado o no que se someta la cuestión al Tribunal de Justicia. En efecto, como la responsabilidad de la futura resolución judicial recae en el órgano jurisdiccional nacional, es a este órgano —y únicamente a él—a quien corresponde apreciar, habida cuenta de las particularidades de cada asunto, tanto la necesidad de una petición de decisión prejudicial para poder emitir su fallo como la pertinencia de las cuestiones que plantea al Tribunal de Justicia.

Por otro lado, el TEDH también dedicó parte de la sentencia a analizar la jurisprudencia del TJUE a este respecto, como el caso S.r.l. CILFIT and Lanificio di Gavardo S.p.a. v. Ministry of Health ${ }^{50}$, en el cual el TJUE señaló claramente en referencia al art. TFUE (anteriormente el art. 177) lo siguiente:

Habida cuenta del conjunto de estos razonamientos, ha de responderse a la Corte suprema di cassazione que el párrafo tercero del articulo 177 debe ser interpretado en el sentido de que un órgano jurisdiccional cuyas decisiones no son susceptibles de ulterior recurso judicial de Derecho interno, cuando se suscita ante él una cuestión de Derecho comunitario, ha de dar cumplimiento a su obligación de someter dicha cuestión al Tribunal de Justicia, a menos que haya comprobado que la cuestión suscitada no es pertinente, o que la disposición comunitaria de que se trata fue ya objeto de interpretación por el Tribunal de Justicia, o que la correcta aplicación del Derecho comunitario se impone con tal evidencia que no deja lugar a duda razonable alguna; la existencia de tal supuesto debe ser apreciada en función de las características propias del Derecho comunitario, de las dificultades particulares que presenta su interpretación y del riesgo de divergencias de jurisprudencia en el interior de la Comunidad.

49 Recomendaciones, a los órganos jurisdiccionales nacionales, relativas al planteamiento de cuestiones prejudiciales (2016/C 439/01) (DO C439, de 25.11.2016, p.1).

50 Sentencia de 6 de octubre de 1982, CILFIT, C-283/81, EU:C:1982:335. 
Asimismo, el TEDH también hizo referencia a otros tres casos en los que el TJUE había reforzado la capacidad de los tribunales nacionales de decidir qué casos ameritaban una solicitud de cuestión prejudiciales y qué casos no ${ }^{51}$.

El TEDH consideró que en una decisión o sentencia que declaraba inadmisible o desestimaba un recurso de casación se consideraba inherente el rechazo a la solicitud de cuestión preliminar, por cuanto se entendía que dicho recurso no presentaba una cuestión legal que necesitara ser determinada ${ }^{52}$.

Asimismo, y de manera concordante con la jurisprudencia relevante del TJUE, los tribunales nacionales que actuaban como última instancia no tenían la obligación de tramitar una solicitud de cuestión prejudicial sobre la interpretación de legislación de la UE en los casos en los que la respuesta a dicha cuestión no tuviera ningún efecto en el resultado del caso.

A la vista de lo anterior, el TEDH consideró que, en el contexto de los procedimientos sumarios previstos en los ya citados arts. 80 y 81 de la Ley de Organización Judicial, no se produciría ninguna violación del art. 6.1 en aquellos casos en los que un recurso de casación fuera desestimado o declarado inadmisible mediante razones sucintas, siempre y cuando se adoptaran en ausencia de arbitrariedad o manifiesta irracionalidad.

\section{ESPAÑA Y EL TRIBUNAL EUROPEO DE DERECHOS HUMANOS}

A continuación realizaremos un somero repaso de las sentencias más relevantes publicadas en este primer cuatrimestre de 2018 en relación con España.

En primer lugar, analizaremos la sentencia recaída en el caso López $R$ ibalda c. España ${ }^{53}$, cuyo recuro frente a la Gran Sala ha sido recientemente admitido y, por tanto, esta deberá emitir una sentencia al respecto a la mayor brevedad una vez celebrada la oportuna audiencia.

Las demandantes trabajaban como cajeras en una gran cadena de supermercados. A comienzos del año 2009 el encargado de la tienda (en adelante, el encargado) comenzó a detectar una serie de descuadres en las cajas que habían ocasionado unas importantes pérdidas. A la vista de lo anterior, el empleador decidió instalar dos tipos de cámaras de videovigilancia. Unas cámaras estaban

51 Sentencias de 9 de octubre de 2008, Katz, C-404/07, EU:C:2008:553; de 9 de noviembre de 2010, B Pénzügyi Lízing Zrt, C-137/08, EU:C:2010:659; y de 15 de marzo de 2017, Aquino, C-3/16, EU:C:2017:209.

52 Ibid., párrs. 50 a 53.

53 López Ribalda v. Spain, nos. 1874/13 8567/13. 
orientadas hacia las salidas del supermercado y eran visibles. Se informó a los trabajadores y a los clientes de la existencia de dichas cámaras. A su vez, también se instalaron una serie de cámaras secretas orientadas a los puestos de los cajeros y cajeras. Ni los trabajadores ni ningún representante de los trabajadores fueron informados de la existencia de dichas cámaras. Las cámaras grababan a todas horas y a todo el personal en las cajas.

Los días 25 y 29 de junio de 2009 las demandantes fueron convocadas a una reunión con el encargado y el delegado sindical, en las que se les enseñó un vídeo que mostraba cómo simulaban pasar alimentos de sus compañeros y no cobrarlos o cobrar productos para posteriormente cancelar los recibos.

En dichas reuniones las demandantes reconocieron los hechos. Las demandantes fueron despedidas. Tres de las demandantes firmaron un acuerdo transaccional en el que se comprometían a no iniciar acciones legales contra el despido, a cambio de que la empresa no iniciara acciones penales en su contra. Dos de las demandantes no firmaron dicho acuerdo.

Todas las demandantes interpusieron una demanda por despido improcedente alegando que los despidos se basaban en unas grabaciones obtenidas sin haberles informado previamente de la existencia de unas cámaras secretas. Dichas grabaciones habrían infringido su derecho fundamental a la intimidad y a la propia imagen. Las demandantes argumentaron que, siendo ilícita la prueba en cuestión y siendo la única prueba tenida en cuenta para decretar la procedencia del despido, no había existido prueba de cargo que justificara el despido.

En la vista de los juicios celebrados ante el Juzgado de lo Social de Granollers n. ${ }^{\circ} 1$ (en adelante, Juzgado de lo Social) fueron reproducidos como prueba los susodichos vídeos. El 20 de enero de 2010 el Juzgado de lo Social dictó sendas sentencias en virtud de las cuales declaraba que los despidos habían sido procedentes. Gran parte de la fundamentación del fallo recayó sobre los hechos delictivos cometidos por las demandantes, lo cual había sido acreditado por los vídeos y por varias testificales. Asimismo, el Juzgado de lo Social consideró que el uso de videovigilancia estaba amparado constitucionalmente, tal y como ya lo había señalado el Alto Tribunal en su sentada jurisprudencia (entre otras, STC n. ${ }^{\circ}$ 186/2000). La medida, si bien afectaba al derecho a la vida privada de las demandantes, había sido considerara constitucional toda vez que: (1) era susceptible de conseguir el objetivo propuesto (juicio de idoneidad); (2) necesaria, en el sentido de que no existía otra medida más moderada para la consecución de tal propósito con igual eficacia (juicio de necesidad) y (3) equilibrada, toda vez que se derivaban de ella más beneficios o ventajas para el interés general que perjuicios sobre otros bienes o valores en conflicto (juicio de proporcionalidad en sentido estricto). 
Las demandantes recurrieron ante el Tribunal Superior de Justicia de Cataluña (en adelante, el TSJ), el cual desestimó el recurso y condenó a las demandantes al pago de las costas judiciales. Las demandantes recurrieron en casación y en amparo. Todos los recursos fueron desestimados. Finalmente, las demandantes acudieron ante el TEDH e interpusieron una demanda alegando que se había producido una violación de los arts. 6 y 8 del Convenio.

En lo que respecta al pronunciamiento del Tribunal, se debe señalar que en el presente caso el Gobierno reconoció efectivamente que la videovigilancia se había realizado en violación de la Ley Orgánica de Protección de Datos (en adelante, LOPD) y que ello suponía una violación del art. 8 del Convenio. No obstante, el Gobierno arguyó que dicha violación no era imputable al Estado español, toda vez que había sido cometida por una empresa privada. A este respecto, el Tribunal recordó que, si bien el propósito principal del art. 8 es proteger a los ciudadanos de las injerencias que pudieran realizar las autoridades públicas (obligación negativa), lo cierto es que dicha protección también se amplía a la obligación positiva de proteger a las personas bajo su jurisdicción frente a terceros. Lo anterior implica la adopción de medidas orientadas a asegurar el respeto a la vida privada en la esfera de las relaciones entre individuos.

El Tribunal, a continuación, observó que, efectivamente, la grabación y procesamiento de las imágenes, las cuales pertenecían a la esfera privada de la persona, fueron tratadas por numerosas personas que trabajaban en la empresa antes tan siquiera de que las demandantes fueran informadas de la existencia de dichos vídeos.

El Tribunal hizo especial hincapié en el hecho de que, en el momento de la instalación del sistema de videovigilancia, el art. 5 de la LOPD claramente establecía el derecho de las demandantes a ser informadas modo expreso, preciso e inequívoco sobre:

a) La existencia de un fichero o tratamiento de datos de carácter personal, de la finalidad de la recogida de éstos y de los destinatarios de la información”

b) Del carácter obligatorio o facultativo de su respuesta a las preguntas que les sean planteadas.

c) De las consecuencias de la obtención de los datos o de la negativa a suministrarlos.

d) De la posibilidad de ejercitar los derechos de acceso, rectificación, cancelación y oposición. 
e) De la identidad y dirección del responsable del tratamiento o, en su caso, de su representante.

También hizo referencia al art. 3 de la Instrucción 1/2006 de la Agencia Española de Protección de Datos, el cual específicamente señala que:

Los responsables que cuenten con sistemas de videovigilancia deberán cumplir con el deber de información previsto en el artículo 5 de La Ley Orgánica 15/1999, de 13 de diciembre. A tal fin deberán:

a) Colocar, en las zonas videovigiladas, al menos un distintivo informativo ubicado en lugar suficientemente visible, tanto en espacios abiertos como cerrados y

b) Tener a disposición de los/las interesados/as impresos en los que se detalle la información prevista en el artículo 5.1 de la Ley Orgánica 15/1999.

El contenido y el diseño del distintivo informativo se ajustará a lo previsto en el Anexo de esta Instrucción.

El Tribunal señaló que el hecho de que el empleador no hubiera cumplido con dichas obligaciones era claro, tal y como lo habían declarado los tribunales internos ${ }^{54}$. A lo anterior se añadió el hecho de que el Gobierno reconoció dicho incumplimiento. El Tribunal quiso destacar además que, en un contexto en el que existe una legislación tan clara al respecto, «la expectativa de privacidad» era muy razonable $e^{55}$. El Tribunal hizo también referencia a la decisión de inadmisibilidad recaída en el caso Köpke $e^{56}$, un caso sin duda parecido al presente, pero con ciertas diferencias. El TEDH vino a señalar que en Köpke no existía una legislación tan clara como la española que protegiera la obtención y almacenamiento de datos de una manera tan específica. Asimismo, y ya entrando en el análisis de proporcionalidad, la sentencia señaló que, mientras que en Köpke existieron unas sospechas sobre determinadas personas, en el presente caso se optó por videovigilar de manera secreta a toda la plantilla durante semanas ${ }^{57}$.

En conclusión, el Tribunal consideró que la videovigilancia fue contraria al art. 8 del Convenio, destacando que los derechos del empleador se podrían haber garantizado igualmente, al menos hasta cierto punto, si se hubiera

54 Ibid., párr. 65.

55 Ibid., párr. 67.

56 Köpke v. Germany (dec.), no. 420/07.

57 López Ribalda, supra, párr. 68. 
informado a los demandantes «aunque fuera de una manera general» de la instalación de un sistema de videovigilancia y de la información exigida por la $\mathrm{LOPD}^{58}$.

En lo que respecta a la violación del art. 6 del Convenio en cuanto a la admisión de una prueba contraria al art. 8 del CEDH, el Tribunal destacó que las grabaciones no habían sido el único elemento de prueba que acreditaba el hurto cometido por las demandantes. Así, dicha conclusión fue también sostenida por las testificales de otros compañeros de trabajo, el encargado del supermercado, el representante sindical así como el representante de la empresa. Por tanto, el TEDH no contaba con ningún elemento de prueba que indicara que los derechos de defensa de las demandantes no fueron respetados ${ }^{59}$.

Por otro lado, el Tribunal también se pronunció sobre la queja interpuesta por la tercera, cuarta y quinta demandante alegando que la admisión de los acuerdos transaccionales había sido contraria al art. 6 del Convenio, toda vez que dichos acuerdos se habían adoptado mediante coacción. El Tribunal consideró que no existía razón alguna para cuestionar la valoración de la prueba realizada por los tribunales internos ya que, de lo contrario, estaría actuando como un "tribunal de cuarta instancia» ${ }^{60}$. Por último, el Tribunal también declaró inadmisible una queja del primer demandante aduciendo que las sentencias recaídas a nivel interno no habían estado suficientemente motivadas ${ }^{61}$.

También debemos destacar la sentencia dictada en el caso Cuenca Zarzoso c. España ${ }^{62}$, en la que el Tribunal tuvo oportunidad de analizar, tal y como ya lo hizo en la sentencia Moreno Gómez c. España $a^{63}$, las obligaciones positivas del Estado español en relación con los ruidos producidos por establecimientos de ocio nocturno.

El demandante, nacido en 1930, vive en un barrio residencial de Valencia desde el año 1962. Desde 1974 el Ayuntamiento de Valencia había permitido la apertura de establecimientos de ocio tales como bares, pubs y discotecas en la zona. En vista de los problemas causados por el ruido, el Ayuntamiento decidió, el 22 de diciembre de 1983, no autorizar la apertura de más establecimientos en la zona. No obstante, la resolución nunca se hizo efectiva y se fueron autorizando nuevas licencias.

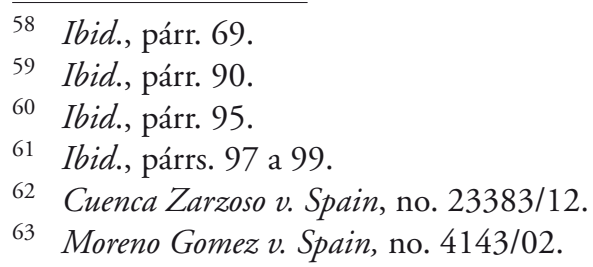


En el año 1994 el demandante se convirtió en presidente de la asociación de vecinos del barrio donde residía. Desde dicho puesto, y en un intento de mejorar la situación de contaminación acústica tanto para él como para sus vecinos, interpuso varias demandas ante el Ayuntamiento y, a su vez, solicitó la retirada de las licencias comerciales de varios establecimientos.

En vista de que los niveles de contaminación acústica no disminuían, el demandante decidió instalar un sistema de doble acristalamiento en las ventanas, así como un sistema de aire acondicionado debido a las altas temperaturas causadas por la necesidad de tener las ventanas permanentemente cerradas en verano.

Con fecha 14 de junio de 1999 el demandante interpuso una reclamación por responsabilidad patrimonial ante el Ayuntamiento. El demandante invocó los arts. 15 (derecho a la vida y a la integridad física) 18.2 (derecho a la inviolabilidad del domicilio) de la Constitución y solicitó una indemnización por los gastos ocasionados así como por daños materiales y morales.

Cabe señalar que, mientras tanto, el 16 de noviembre de 2004, el TEDH había dictado una sentencia de violación en el asunto Moreno Gómez v. Espa$\tilde{n} a^{64}$, la cual no solo versaba sobre hechos muy similares, sino que además los mismos tuvieron lugar en el mismo barrio que el del demandante.

En el procedimiento ante el Tribunal Constitucional, el Ministerio Fiscal alegó que se habían vulnerado los arts. 15 y 18.2 de la Constitución, indicando que el TEDH ya había abordado este tema en el citado asunto Moreno Gómez, que había tratado la misma situación sufrida por el vecino del demandante y había declarado que España había vulnerado el art. 8 del Convenio. El Ministerio Fiscal consideró además que el caso Moreno Gómez y el caso del demandante eran análogos tanto respecto a los hechos como en cuanto al objeto y al fondo, lo que en principio era suficiente para dictar una sentencia sobre el fondo respecto a la supuesta vulneración del derecho a la vida privada y familiar y a la inviolabilidad del domicilio.

No obstante lo anterior, mediante sentencia de 29 de septiembre de 2011, el Pleno del Tribunal Constitucional desestimó el recurso de amparo, alegando que (i) los casos no eran idénticos; (ii) el demandante no había probado que en este caso concreto el ruido en su domicilio superaba el nivel permitido; (iii) el Ayuntamiento había adoptado medidas concretas para reducir la contaminación acústica en el vecindario del demandante; y que (iv) no había quedado probado que sus problemas de salud fuesen directamente provocados por la contaminación acústica. La sentencia no se adoptó por unanimidad, ya que tres de los doce magistrados emitieron votos discrepantes

$64 I d$. 
y señalaron que se había producido una vulneración de los arts. 10.2, 18.1 y 18.2 de la Constitución.

El demandante acudió al TEDH, el cual falló a su favor. Igual que en Moreno Gómez, el Tribunal observó que el presente caso no se refería a la injerencia por parte de las autoridades públicas en el derecho al respeto al domicilio, sino respecto a su incumplimiento en acabar con las infracciones producidas por terceros del derecho invocado por el demandante ${ }^{65}$. El Tribunal observó que el demandante residía en una zona expuesta a molestias nocturnas, lo cual «claramente desestabiliza[ba] al demandante en su vida diaria, sobre todo los fines de semana ${ }^{66}$.

El Tribunal destacó el hecho de que el Ayuntamiento era consciente de que el volumen de ruido en este vecindario en concreto superaba los niveles permitidos. Estos elevados niveles acústicos continuaron durante varios años tras la declaración del barrio como zona acústicamente saturada, tal y como lo confirmaron los informes oficiales aportados por los servicios municipales, y fue además reconocido por el Gobierno ${ }^{67}$. Es por ello que el TEDH declaró que sería "excesivamente formalista» requerir al demandante para que aportara pruebas individualizas y específicas respecto al ruido sufrido en su piso, ya que las autoridades municipales habían designado el barrio de residencia del demandante como zona acústicamente saturada ${ }^{68}$.

El TEDH señaló que, si bien el Ayuntamiento tomó diversas medidas para resolver el problema de contaminación acústica en la zona, lo cierto es que dichas medidas fueron insuficientes ${ }^{69}$. Por tanto, el Tribunal concluyó que el Estado español incumplió con su obligación positiva de garantizar el derecho del demandante al respeto de su domicilio y su vida privada, vulnerando así el art. 8 del Convenio ${ }^{70}$.

Por otro lado, el Tribunal también dictó una interesante sentencia en el caso Portu Juanenea y Sarasola Yarzabal c. España ${ }^{71}$.

Con fecha 6 de enero de 2008 los demandantes fueron arrestados en la localidad de Mondragón (Guipúzcoa, País Vasco) por miembros de la Guardia Civil especializados en la lucha contra el terrorismo. Según la versión de los demandantes, una vez introducidos en los vehículos, los mismos fueron

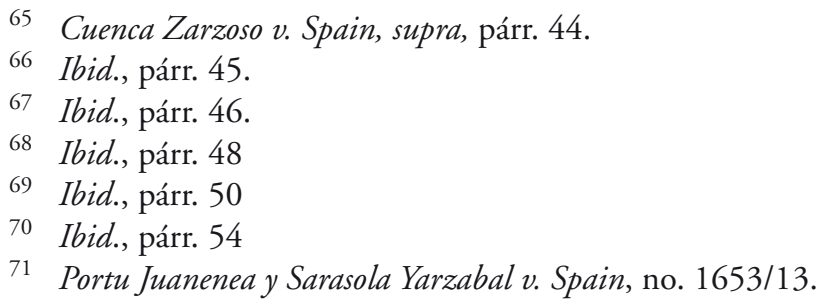


golpeados, insultados y amenazados por los guardias civiles que los custodiaban. Asimismo, los guardias civiles que custodiaban al segundo demandante le habrían bajado del vehículo y le habrían tirado cuesta abajo en dirección al río. Además, le habrían amenazado y propinado patadas en los costados y en las piernas, así como puñetazos en todo el cuerpo. A continuación habrían sacado al primer demandante del vehículo y le habrían dado patadas en las piernas, puñetazos en el vientre y le habrían sumergido dos o tres veces la cabeza en el agua antes de introducírsela en el río por última vez, sujetándole por los tobillos y haciéndole tragar agua. Durante el trayecto, el primer demandante continuó recibiendo bofetadas y puñetazos en la cabeza.

El 7 de enero de 2008 los demandantes fueron conducidos a continuación a San Sebastián, donde fueron reconocidos por dos médicos forenses del Instituto Vasco de Medicina Legal, I.S. y A.S., quienes derivaron inmediatamente al primer demandante al hospital Aránzazu de San Sebastián. El primer demandante ingresó en la unidad de cuidados intensivos de dicho hospital en estado grave, y estuvo hospitalizado del 7 al 11 enero de 2008. El segundo demandante fue trasladado a Madrid en coche, donde las amenazas y golpes habrían continuado.

La versión del Gobierno sobre la detención de los demandantes no coincidía con lo relatado por estos. Así, según el Gobierno, los demandantes fueron detenidos en el marco de una operación antiterrorista. Los miembros de la Guardia Civil dieron el alto a los demandantes y les pidieron su identificación y que abrieran sus mochilas para registrarlas, momento en el cual habrían intentado escapar. Los demandantes se habrían caído al suelo y se habría producido un forcejeo, tal y como así relataron en sus primeras declaraciones ante los médicos forenses.

En lo que respecta al procedimiento interno surgido a raíz de estos hechos, el TEDH observó que se abrió un procedimiento de investigación por presuntos delitos de tortura contra quince agentes de la Guardia Civil que habían participado en el arresto y la detención de los demandantes. En virtud de la sentencia de 30 de diciembre de 2010, la Audiencia Provincial de Guipúzcoa condenó al sargento C. a una pena de cuatro años de prisión por dos delitos de graves torturas, a una pena de seis meses de prisión por un delito de lesiones y a ocho días de localización permanente por una falta de lesiones. Condenó a E. a una pena de dos años de prisión por un delito de torturas graves y a una pena de seis meses de prisión por un delito de lesiones. Por último, condenó a G. y M. a penas de dos años de prisión por un delito de torturas graves y a ocho días de localización permanente por una falta de lesiones. El sargento C., G., E. y M. fueron igualmente condenados a pagar 18000 euros al primer demandante y 6000 euros al segundo demandante en concepto de daños y perjuicios. Los otros once agentes de la Guardia Civil que formaban 
parte del dispositivo de detención en cuestión fueron absueltos. Cabe señalar que, para llegar a tal fallo, la Audiencia Provincial de Guipúzcoa tuvo en cuenta las declaraciones de los demandantes y estimó que no había indicios de que los interesados hubieran mentido en sus declaraciones por el simple hecho de su pertenencia a ETA o por la estrategia de esta organización consistente en presentar falsas acusaciones contra las fuerzas de seguridad españolas.

Los cuatro guardias civiles, la Fiscalía y los demandantes recurrieron en casación. En virtud de dos sentencias del 2 de noviembre de 2011, el Tribunal Supremo casó y revocó la sentencia recurrida, absolvió a los cuatro guardias civiles condenados anteriormente, todo ello con base en una modificación parcial de los hechos declarados probados por la sentencia a quo, y considerando superfluo examinar los demás aspectos del recurso. Además, consideró que los siguientes elementos no habían sido probados, esto es: las circunstancias - no violentas - de la detención de los dos demandantes descritas en la sentencia de la Audiencia Provincial, el paso por la pista forestal y los sucesos que se habrían producido en ese lugar, y el hecho de que las lesiones descritas eran a resultas de las causas invocadas en la sentencia a quo. Los demandantes interpusieron un incidente de nulidad y, posteriormente, un recurso de amparo. Ambos fueron desestimados.

En consecuencia, los demandantes acudieron ante el TEDH e invocaron los arts. 3 y 6.1 del Convenio. Sostuvieron haber sido víctimas de torturas y de malos tratos durante su arresto y en los primeros momentos de su detención preventiva incomunicada a manos de la Guardia Civil. Asimismo, denunciaron la ausencia de condena de los autores de los actos de tortura y la política de impunidad del Estado español al respecto. En particular, los demandantes se quejaron de la nueva valoración de las pruebas realizada por el Tribunal Supremo.

El TEDH señaló en primer lugar que el art. 3 del Convenio protegía «uno de los valores fundamentales de las sociedades democráticas» ${ }^{72}$ y se considera un «derecho absoluto e inalienable estrechamente vinculado al respeto de la dignidad humana", que además no admite restricciones y no es derogable, incluso "en caso de peligro público que amenace la vida de la nación", lo que incluye situaciones que versan sobre la lucha contra el terrorismo y el crimen organizado ${ }^{73}$.

72 Ibid., párr. 69. Véase, asimismo y especialmente, Selmouni v. France [GC], no 25803/94, párr. 95; Mocanu and others v. Rumania [GC], nos. 10865/09, 45886/07 y 32431/08, párr. 315; y Bouyid v. Belgium [GC], 23380/09, párr. 81.

73 Ibid., párr. 69. 
En el presente caso existía una fuerte controversia entre los hechos relatados por los demandantes y los manifestados por el Gobierno. A este respecto, el TEDH recordó que en situaciones de personas bajo custodia por parte del Estado, cualquier herida producida en este periodo da lugar a fuertes presunciones de hecho en favor de la víctima y, por tanto, la carga de la prueba recae entonces sobre el Gobierno en el sentido de que tendrá la obligación de dar una explicación «satisfactoria y convincente» y con las pruebas oportunas para poder cuestionar el relato de la víctima ${ }^{74}$.

Sentado lo anterior, el TEDH observó que los primeros informes elaborados por los médicos forenses indicaban que «los demandantes presentaban múltiples lesiones en las regiones cefálica, torácica y abdominal, así como en las extremidades superiores e inferiores en lo que respecta al primer demandante ${ }^{75}$. Asimismo, también existían otros dos informes que habían concluido que existían elementos indicando que las lesiones constatadas habían podido producirse conforme a las declaraciones de los demandantes ${ }^{76}$. Es más, los médicos forenses también analizaron la versión defendida por la Guardia Civil y consideraron que dicha versión no era compatible con la mayoría de lesiones que tenían los demandantes.

El TEDH puso especial énfasis en el análisis realizado por el Tribunal Supremo que justificaba la absolución de los guardias civiles, observando que dicho Tribunal «no se ha[bía] dedicado a valorar de manera alguna la forma ni el momento en las que estas lesiones [en concreto, la fractura de las costillas] habían sido causadas al primer demandante» ${ }^{77}$. El TEDH observó además que el Tribunal Supremo se habría limitado a descartar la versión de los demandantes sin determinar el origen de las lesiones sufridas que constaban en los informes médicos. Es más, incluso en el caso de que se diera por válida la versión de los guardias civiles, el Tribunal Supremo no examinó debidamente si el recurso a la fuerza física había sido el estrictamente necesario y proporcional $^{78}$.

A la vista de lo anterior, el Tribunal concluyó que había quedado suficientemente acreditado que las lesiones que figuraban en los informes médicos se produjeron y que «ni las autoridades nacionales ni el Gobierno ha[bían] aportado argumentos convincentes o creíbles que p[udieran] explicar o justificar

\footnotetext{
74 Ibid., párr. 73.

75 Ibid., párr. 76.

76 Ibid., párr. 77

77 Ibid., párr. 80.

78 Ibid., párr. 81.
} 
en las circunstancias del caso las lesiones sufridas por los demandantes» ${ }^{79}$. Por tanto, el Tribunal declaró que se había producido una violación tanto del aspecto material del art. 3 (por un tratamiento inhumano y degradante), así como del aspecto procesal (por el análisis legal y fallo realizado por el Tribunal Supremo).

Es importante destacar que el Tribunal declaró expresamente que los tratos otorgados a los demandantes se calificaban como tratos inhumanos y degradantes, y no torturas, tal y como así lo solicitaban los demandantes, todo ello debido a que (1) los demandantes no alegaron que las lesiones en cuestión hubieran tenido sobre ellos consecuencias a largo plazo y (2) en «ausencia de prueba concluyente relativa a la finalidad de los tratos infligidos» ${ }^{80}$.

El interés del presente caso radica en el hecho de que es la primera vez que España es condenada por violar el art. 3 del Convenio en su vertiente sustantiva, ya que hasta ahora todas las condenas similares habían sido únicamente por violación de su vertiente procesal.

Por último, también destacaremos la sentencia relativa al caso Stern Taulats y Roura Capellera c. España $a^{81}$, que versó sobre la quema de unas fotos del rey en un acto de protesta, así como el ámbito de protección del derecho a la libertad de expresión amparado por el art. 10 del Convenio.

El 13 de septiembre de 2007, con motivo de la visita institucional del rey de España a la ciudad de Girona, los demandantes quemaron una fotografía suya colocada boca abajo en el curso de una concentración en la plaza de Vino de Girona. A dicha concentración le había precedido una manifestación encabezada por una pancarta que contenía el mensaje «300 años de Borbones, 100 años combatiendo la ocupación española». Los demandantes iban con el rostro tapado para no ser identificados. Durante la quema de la foto los demandantes fueron jaleados con diferentes gritos por las varias decenas de personas que se habían reunido en la citada plaza.

A raíz de dichos acontecimientos los demandantes fueron procesados penalmente. Con fecha 9 de julio de 2008, la Audiencia Nacional condenó a los demandantes por un delito de injurias contra la Corona proscrito en el art. 490.3 del Código Penal, imponiéndoles una pena de quince meses de prisión e inhabilitación de sufragio pasivo durante el tiempo de la condena y al pago por mitad de las costas. No obstante, como quiera que los demandantes no

\footnotetext{
79 Ibid., párr. 83 .

80 Ibid., párr. 84.

81 Stern Taulats y Roura Capeller v. Spain, nos. 51168/15 and 51186/15. Cabe señalar que dicha sentencia no ha alcanzado, en el momento de redacción de la presente crónica, firmeza, de conformidad con lo estipulado en el art. 44.2 del Convenio.
} 
habían sido nunca condenados a una pena por delito o falta anteriormente, les fue impuesta una multa de 2700 euros sustitutiva de la pena de prisión a cada uno de ellos. Ahora bien, conforme a lo estipulado en el art. 88 del Código Penal, en caso de impago, total o parcial, de la multa, los demandantes cumplirían la pena de prisión impuesta.

Los demandantes interpusieron el correspondiente recurso y con fecha 5 de diciembre de 2008 el Pleno de la Sala de lo Penal de la Audiencia Nacional confirmó esta sentencia. Seis de los dieciséis Magistrados del Pleno formularon votos particulares.

A continuación, los demandantes recurrieron en amparo ante el Tribunal Constitucional, denunciando haber sido objeto de una vulneración de los derechos a la libertad de expresión y a la libertad de opinión amparados por la Constitución española. El 22 de julio de 2015 el Tribunal Constitucional dictó su sentencia desestimando el recurso de amparo y concluyendo que el acto que se les reprochaba a los demandantes no se podía amparar en el ejercicio de los derechos a la libertad de expresión y a la libertad de opinión, toda vez que los interesados habían exhortado al odio y a la violencia contra el rey y la monarquía.

Los demandantes acudieron a continuación ante el TEDH e invocaron el art. 10 del Convenio, alegando que la sentencia por la que se les declaraba culpables de injurias contra la Corona constituía una vulneración injustificada de su derecho a la libertad de expresión.

El Tribunal señaló en primer lugar que la libertad de expresión constituía «uno de los fundamentos esenciales de una sociedad democrática, una de las condiciones primordiales de su progreso y del desarrollo de cada uno. Vale no sólo para las "informaciones" o "ideas" acogidas favorablemente o que se consideran inofensivas o resultan indiferentes, sino también para las que hieren, ofenden o importunan", toda vez que "así lo requiere el pluralismo, la tolerancia y el espíritu de apertura sin los cuales no existe ninguna "sociedad democrática» ${ }^{82}$.

Asimismo, el Tribunal recalcó que, si bien la libertad de expresión lleva aparejada unas excepciones, las mismas requieren una interpretación restrictiva, «y la necesidad de restringirla debe estar motivada de forma convincente» ${ }^{83}$. A este respecto, el TEDH insistió en el hecho de que el art. 10.2 del Convenio no deja apenas «margen para restricciones a la libertad de expresión

82 Ibid., párr. 30. Véase también, Handyside c. Reino Unido, 7 de diciembre de 1976, párr. 49, serie A, no. 24, y Lindon, Otchakovsky-Laurens y July c. Francia [GS], no. 21279/02 y 36448/02, párr. 45, CEDH 2007-IV.

83

Ibid., párr. 31. 
en el ámbito del discurso y del debate político —en el que esta adquiere la más alta importancia - o cuestiones de interés general ${ }^{84}$, si bien el ámbito de la crítica a este respecto no se puede considerar como ilimitada y que en ocasiones el Estado puede sancionar, incluso prevenir, todas las formas de expresión que propaguen, inciten, promuevan o justifiquen el odio basado en la intolerancia (incluida la intolerancia religiosa), si se vela por que estas «formalidades», «condiciones", «restricciones» o "sanciones» impuestas sean proporcionales a la finalidad legítima perseguida ${ }^{85}$.

En lo que respecta a la compatibilidad de una pena de prisión por la comisión de una infracción en el marco del debate político, el TEDH recordó que la misma solo era compatible en unas circunstancias excepcionales donde el elemento esencial que se debiera considerar era el hecho de que el discurso incitara al uso de la violencia o que constituyera un discurso de odio ${ }^{86}$.

A la hora de aplicar la asentada jurisprudencia a este respecto al caso concreto, el TEDH observó primeramente que el acto que había sido sancionado por los tribunales nacionales se enmarcaba en el ámbito de la «crítica política, y no personal, de la institución de la monarquía en general y en particular del Reino de España como nación ${ }^{87}$. A continuación, el TEDH consideró que el hecho de que se utilizara una fotografía de grandes dimensiones, que se colocara boca abajo y que se quemara (elementos tenidos en cuenta por el Tribunal Constitucional para considerar el acto como un discurso del odio o discurso que incita a la violencia) no constituían nada más que elementos simbólicos que tenían una «relación clara y evidente con la crítica política concreta expresada por los demandantes, que se dirigía al Estado español y su forma monárquica: el símbolo del Rey de España Jefe del aparato estatal ${ }^{88}$.

$\mathrm{Al}$ contrario de lo dictaminado por el Tribunal Constitucional, el TEDH consideró que la intención de los demandantes no era la de incitar a la comisión de actos de violencia contra el rey, sino que este tipo de actos debía ser interpretado como "expresión simbólica de una insatisfacción y de una protesta ${ }^{89}$.

Asimismo, en lo que respecta a la sanción penal que le fue impuesta a los demandantes, el Tribunal consideró, con base en su reiterada jurisprudencia

\footnotetext{
84 Ibid., párr. 32.

85 Ibid., párr. 33. Véase también, en lo que atañe al discurso del odio y a la apología de la violencia, Sürek v. Turkey (no. 1) [GC], no. 26682/95, párr. 62, y Gündüz v. Turkey, no. 35071/97, párr. 40.

86 Ibid., párr. 34.

87 Ibid., párr. 36.

88 Ibid., párr. 38

89 Ibid., párr. 39.
} 
al respecto, que dicha pena constituyó una injerencia en la libertad de expresión desproporcional a la finalidad legítima perseguida, la cual además no era necesaria en una sociedad democrática ${ }^{90}$. A la vista de lo anterior, el TEDH concluyó que se produjo una violación del art. 10 del Convenio.

$90 \quad$ Ibid., párr. 42. 